Revista de Educação e Pesquisa em Contabilidade

Journal of Education and Research in Accounting

Revista de Educación e Investigatión en Contabilidad
REPeC, Brasília, v. 6, n. 4, art. 4, p. 399-418, out./dez. 2012 Disponível online em www.repec.org.br

ISSN 1981-8610

\title{
Cooperação Acadêmica: Análise de Publicações em Eventos Científicos sobre Ensino e Pesquisa em Contabilidade
}

\author{
Emerson Muniz Freitas \\ Mestre em Contabilidade (UFPR) \\ Av. Prefeito Lothário Meissner, 632, Sala 120, Jardim Botânico, Curitiba (PR) \\ E-mail: emersonmfreitas@gmail.com
}

\section{Vicente Pacheco}

Doutor em Engenharia de Produção (UFSC)

Professor Adjunto da Universidade Federal do Paraná

Av. Prefeito Lothário Meissner, 632, Sala 120, Jardim Botânico, Curitiba/PR

E-mail:vpacheco@ufpr.br

\section{Regina Maria Karolkievicz}

Mestre em Contabilidade (UFPR)

Av. Prefeito Lothário Meissner, 632, Sala 120, Jardim Botânico, Curitiba/PR

E-mail:reginakarol@hotmail.com

\section{Edson Paes Sillas}

Mestre em Contabilidade (UFPR)

Av. Prefeito Lothário Meissner, 632, Sala 120, Jardim Botânico, Curitiba/PR

E-mail:edsonsilas@yahoo.com.br

\section{Resumo}

O conhecimento científico é desenvolvido de forma social, a partir da colaboração entre os atores envolvidos no processo. Partindo dessa premissa, o presente estudo tem por finalidade mapear, por meio da análise de redes sociais, as interações colaborativas nos estudos desenvolvidos versando sobre Ensino e Pesquisa em Contabilidade. Para isso, analisaram-se 215 artigos que versavam sobre o assunto em pauta, publicados no Enanpad, no Congresso USP de Controladoria e Contabilidade e no Anpcont. Foi feito uso da metodologia de análise de redes sociais, por intermédio da qual foram desenvolvidas as estruturas de parceria colaborativa no período analisado, compreendido entre 1999 e 2009. Aliado a isso, buscou-se verificar se os indicadores de centralidade dos pesquisadores estão associados com a sua produção, sendo utilizado para esse o teste não paramétrico $p$ de Spearman. A centralidade identifica os atores mais importantes em uma rede social, em que, quanto mais centrais, mais relevante a contribuição de determinados indivíduos. Com o estudo realizado, foi possível verificar os pesquisadores e instituições de ensino superior mais importantes para a área, tanto no

Editado em Português, Inglês e Espanhol. Versão original em Português.

Recebido em 01/09/2010. Pedido de Revisão em 12/10/2011. Resubmetido em 23/01/2012. Aceito em 29/06/2012 por Valcemiro Nossa (Editor). Publicado em 30/11/2012. Organização responsável pelo periódico: CFC/FBC/ABRACICON.

Copyright (C) 2012 REPEC. Todos os direitos, até mesmo de tradução, são reservados. É permitido citar parte de artigos sem autorização prévia, desde que seja identificada a fonte. 
número de autorias quanto na intermediação promovida por estes pesquisadores e instituições. Entre os pesquisadores, aqueles que se destacaram foram Gilberto de Andrade Martins e Edgard Bruno Cornachione Jr., os quais representam os estudiosos mais prolíficos. Ambos são vinculados à Universidade de São Paulo, Instituição de Ensino Superior (IES) responsável pelo maior número de autorias no período. Aliado a isso, por intermédio da análise da associação dos indicadores de centralidade com o volume da produção científica dos pesquisadores, identificou-se uma associação significativamente positiva. Dessa forma, foi possível verificar que quanto maior a intermediação e os relacionamentos de co-autoria promovidos com outros estudiosos, maior o número de artigos publicados pelos atores investigados.

Palavras-Chave: Redes Sociais; Co-autoria; Conhecimento Científico; Ensino; Pesquisa

\section{INTRODUÇÃO}

Segundo Batistella, Bonacim e Martins (2008), o desenvolvimento das publicações acadêmicas, geralmente, passa por três importantes fases: 1) discussões no âmbito de grupos de pesquisa ou na universidade; 2) apresentações em congressos científicas; e, 3) publicação em periódicos. A publicação dos resultados encontrados se mostra importante, pois é esta a forma que o pesquisador possui para relatar à comunidade acadêmica as suas conclusões (BORBA e MURCIA, 2006). E as pesquisas bibliométricas, com o intuito de verificar o perfil de determinada área, por meio da análise dos artigos desenvolvidos por seus pesquisadores, têm ganhado força (LYRIO, BORBA e COSTA, 2007).

Aliado a essa crescente atenção ao delineamento dos estudos publicados, diversos autores apontam a tendência de aumento no número de trabalhos realizados em co-autoria (LABAND e TOLLISON, 2000; CRONIN, SHAW e LA BARRE, 2003; MOODY, 2004; ACEDO et al., 2006). Para Hudson (1996), a produção de estudos em parceria proporciona um resultado qualitativamente superior aos desenvolvidos isoladamente. Todavia, Guarido Filho, Machado-da-Silva e Gonçalves (2009) afirmam que é importante analisar as relações sociais existentes nessa interação científica, para entender o papel dos atores que participam do processo de criação do conhecimento.

À luz dessas considerações, o presente estudo objetiva mapear, por meio da análise de redes sociais, as interações colaborativas nos estudos desenvolvidos versando sobre Ensino e Pesquisa em Contabilidade. Nessa área de pesquisa, como demonstrado por Espejo et al. (2009), tem-se observado uma grande ascensão quantitativa dos artigos, tornando-se salutar a investigação de como está sendo procedido este desenvolvimento.

Para isso, foram investigados os artigos publicados em três congressos proeminentes na área contábil: 1) Encontro Nacional da Associação de Pós-Graduação em Administração (Enanpad); 2) Congresso USP de Controladoria e Contabilidade; e, 3) Congressos da Associação Nacional dos Programas de Pós-Graduação em Ciências Contábeis (AnpCont). Investigou-se a evolução quantitativa das publicações na área em questão e, em seguida, buscou-se classificar os autores de acordo com o seu volume e a regularidade de sua produção. Por fim, objetivou-se avaliar a existência de associação entre indicadores de centralidade dos pesquisadores e das Instituições de Ensino Superior (IES) em suas respectivas produções científicas.

Após essa breve introdução, são apresentados os aspectos teóricos que fundamentam este estudo na seção dois. Em seguida, realiza-se a descrição dos procedimentos metodológicos adotados na posterior análise dos resultados. Por fim, são elencadas as conclusões encontradas, as limitações observadas e o encaminhamento para futuras pesquisas.

\section{ABORDAGEM DE REDES SOCIAIS EM PESQUISAS BIBLIOMÉTRICAS}

As redes sociais representam um conjunto de atores anônimos que compartilham recursos, materiais ou não, em torno de objetivos e interesses compartilhados (MARTELETO, 2001). Este método de pesquisa sociológica tem sido uma das correntes mais utilizadas atualmente (ROSSONI e GUARIDO 
FILHO, 2007). Seu surgimento data dos estudos sociométricos do psiquiatra romeno Jacob Levy Moreno, e se desenvolveu na sociologia norte-americana, demonstrando ser um importante modelo de pesquisa social (WELLMAN, 1988).

Rossoni, Hocayen-da-Silva e Ferreira Jr. (2008) afirmam que as pesquisas que utilizam a abordagem de redes sociais buscam avaliar a estrutura de relacionamentos entre seus participantes. Para Nelson (1984), os contatos que ligam esses atores podem apresentar características distintas, conteúdos diferentes e estruturas particulares. À medida que padrões de relacionamentos são observados, compreende-se sua conexão com a estrutura social (EMIRBAYER e GOODWIN, 1994).

Esta metodologia de pesquisa vem sendo altamente empregada em estudos que visam analisar características inerentes à publicação científica. O conhecimento científico, de acordo com Rossoni, Hocayen-da-Silva e Ferreira Jr. (2008, p. 1042), “[...] é construído socialmente, influenciado pelos pares que compõem estruturalmente a rede de relações entre as instituições [...]." Portanto, a colaboração entre pesquisadores deve ser encorajada (KATZ e MARTIN, 1997) devido ao compartilhamento de experiências e ideias entre instituições (CRUZ, ESPEJO e GASSNER, 2009).

De acordo com Hudson (1996), a co-autoria pode ser definida como o envolvimento de dois ou mais autores na elaboração de uma pesquisa. Para o autor, a sua principal vantagem encontra-se na divisão do trabalho, permitindo ainda a integração de pesquisadores com diferentes habilidades. Barnett, Ault e Kaserman (1998) acrescentam outras vantagens, como redução no tempo e melhoria na qualidade do artigo.

Diversos autores verificaram o crescimento de artigos publicados de forma colaborativa (LABAND e TOLLISON, 2000; CRONIN, SHAW e LA BARRE, 2003; MOODY, 2004; ACEDO et al., 2006) e este é um assunto que tem despertado o interesse acadêmico (ESPARTEL, BASSO e RECH, 2008). Laband e Tollison (2000) fizeram um levantamento histórico da publicação de pesquisas nas áreas econômicas e biológicas. Os autores realizaram análise dos artigos publicados em co-autoria entre 1950 e 1995 e verificaram um aumento no percentual de artigos publicados com a participação de mais de um autor nas duas áreas investigadas. Enquanto na área econômica o percentual passou de aproximadamente 10\%, em 1950, para 70\%, em 1995; nas pesquisas biológicas, essa participação passou de 30\% para 80\%.

Acedo et al. (2006) verificaram que os estudos desenvolvidos sob esta perspectiva seguem duas linhas: 1) a primeira busca identificar as razões e as consequências da colaboração entre pesquisadores; e, 2) a segunda analisa as redes sociais formadas por esta interação.

$\mathrm{Na}$ segunda linha de pesquisa observada por Acedo et al. (2006), na qual se enquadra o presente estudo, o primeiro trabalho foi desenvolvido por Newman (2001), com enfoque nas ciências naturais (GRAEML et al., 2008). Contudo, este interesse foi logo disseminado por outras áreas do conhecimento, como: ciências físicas (BARABASI et al., 2002), pesquisa digital (LIU et al., 2005), sociologia (MOODY, 2004), estudos organizacionais e estratégia (ACEDO et al., 2006; ROSSONI e MACHADO-SILVA, 2007; WALTER e SILVA, 2008); administração da informação (GRAEML et al., 2008), gestão pública e social (ROSSONI, HOCAYEN-DA-SILVA e FERREIRA Jr., 2008) e marketing (ESPARTEL, BASSO e RECH, 2008).

Diferentes autores, na área de Contabilidade, também fizeram uso da metodologia de redes sociais para verificar a contribuição à ciência proporcionada pela interação acadêmica. Wakefield (2008), por exemplo, mapeou o relacionamento entre journals, analisando, para tal, as citações realizadas, buscando identificar aqueles periódicos mais relevantes para a Ciência Contábil. Essa relevância dos periódicos foi classificada com base no fluxo de conhecimento que cada periódico apresentava, considerando não só as citações diretas, como também o fluxo indireto de conhecimento. Esse fluxo foi mapeado com o auxílio de análise de redes sociais e permitiu que o autor identificasse os periódicos Journal of Accounting Research (JAR) e The Accounting Review (TAR) como os mais relevantes.

Outros estudos podem ser citados para ilustrar o uso da metodologia em questão em trabalhos científicos da área de Contabilidade. Souza et al. (2008) analisaram a cooperação entre IES nos artigos de Contabilidade apresentados no Enanpad, no Anpcont, no Enepq e no Congresso USP de Controladoria e Contabilidade. As autoras concluíram que as IES que possuem programas de pós-graduação (mestrado 


\section{repc}

acadêmico e doutorado) são aquelas que contribuem com maior número de publicações para o desenvolvimento da Ciência Contábil no cenário brasileiro, destacando-se a Universidade de São Paulo (USP). O resultado do estudo corroborou, assim, os achados de Leite Filho (2006), os quais vinculam a produção do conhecimento na área aos programas de pós-graduação, por serem responsáveis pela formação de pesquisadores, mestres e doutores.

Nascimento, Ribeiro e Junqueira (2008) voltaram suas atenções para a abordagem comportamental em Contabilidade Gerencial e observaram que mais de $80 \%$ dos autores identificados na pesquisa publicaram somente um artigo na área. Os autores remeteram-se à Lei de Lotka para explicarem esse fenômeno. Essa Lei fundamenta-se na premissa básica de que "alguns pesquisadores publicam muito e muitos publicam pouco." (VOOS, 1974). Resultado semelhante foi encontrado por Machado, Nascimento e Murcia (2009), que, por sua vez, focaram nos estudos que tratavam sobre Contabilidade Social e Ambiental. Nesse estudo, os autores identificaram que $77 \%$ dos autores publicaram apenas um artigo.

Apesar do grande número de estudos desenvolvidos com a finalidade de verificar características atinentes à cooperação acadêmica no âmbito das pesquisas contábeis, nenhum deles foi elaborado focando especificamente os artigos na área de Ensino e Pesquisa em Contabilidade. Na próxima seção da pesquisa ora apresentada, serão elencados os procedimentos metodológicos adotados para, em seguida, evidenciar os resultados empíricos encontrados.

\section{PROCEDIMENTOS METODOLÓGICOS}

O presente estudo, em um primeiro momento, apresenta caráter descritivo, haja vista que busca, a partir da análise de redes de co-autorias, caracterizar a produção científica na área de Ensino e Pesquisa em Contabilidade. O trabalho assume ainda, em um segundo instante, caráter exploratório, ao investigar a associação existente entre os indicadores de centralidade e a produção científica dos autores.

Como estratégia de coleta de dados, utilizou-se a pesquisa documental. Os artigos investigados foram obtidos nos anais do Encontro Nacional da Associação de Pós-Graduação em Administração (Enanpad), do período compreendido entre 1999 e 2009, nos anais do Congresso USP de Controladoria e Contabilidade, dos anos de 2001 a 2009, e nos anais dos três Congressos da Associação Nacional dos Programas de Pós-Graduação em Ciências Contábeis (AnpCont) já realizados, 2007, 2008 e 2009.

Os trabalhos foram coletados nas diferentes áreas temáticas dos respectivos eventos e, portanto, a busca não se restringiu a área específica para Ensino e Pesquisa. Primeiramente, foi realizada a leitura pelos autores dos resumos dos trabalhos apresentados nos Anais dos Congressos utilizados na pesquisa. Essa primeira análise permitiu selecionar os textos que mereciam uma análise completa do texto, para definição de sua utilização na pesquisa. Após essa análise inicial, os artigos que foram selecionados a partir do resumo foi, integralmente, objeto de análise de dois diferentes autores da presente pesquisa. Havendo divergência entre o parecer dos pesquisadores que analisaram o artigo, um terceiro pesquisador realizava a leitura para decidir se o texto tratava-se, ou não, sobre Ensino e Pesquisa em Contabilidade. Ao final, totalizaram-se 215 artigos.

A coleta de dados quanto à afiliação institucional dos autores foi realizada considerando as informações prestadas no próprio artigo. Quando tal informação era omitida na publicação, recorreu-se ao currículo Lates de cada autor para avaliar a instituição em que estava vinculado no momento da publicação do estudo. Foram tabulados em arquivo eletrônico o evento em que o artigo havia sido apresentado, seus autores, ano e IES de vinculação.

No presente estudo, utilizou-se a análise de redes sociais no intuito de alcançar o objetivo de pesquisa proposto. Segundo Rossoni e Guarido Filho (2007), a condução da análise de redes pode ser realizada sob diversas possibilidades, englobando um grande número de métricas para avaliação das características inerentes aos relacionamentos existentes. As redes de co-autoria e suas análises foram executadas com o auxílio dos programas computacionais Ucinet 6.275 e Pajek 1.02.. Neste estudo, será dado enfoque em dois conjuntos de medidas: centralidade e coesão. 
A centralidade identifica os atores mais importantes em uma rede social, em que, quanto mais centrais, mais relevante é a contribuição de determinados indivíduos. Para esta avaliação, três medidas são utilizadas (WASSERMAN e FAUST, 1994; SCOTT, 2000; HANNEMAN e RIDDLE, 2005): 1) centralidade de grau (degree); 2) centralidade de proximidade (closeness); e, 3) centralidade de intermediação (betweenness).

A centralidade de grau avalia localmente os atores, por meio do número de laços adjacentes que o indivíduo mantém com outros em uma rede (WASSERMAN e FAUST, 1994). Demonstra, portanto, os elementos que estão diretamente relacionados.

$\mathrm{Na}$ centralidade de proximidade, não só os relacionamentos diretos são avaliados, mas, adicionalmente, engloba o conceito de relações indiretas. Esta medida é definida pela função de maior proximidade que um indivíduo possui em relação a todos os outros na rede. Um ator com maior centralidade de proximidade apresenta maiores condições de interagir rapidamente com todos os outros (WASSERMAN e FAUST, 1994; SCOTT, 2000; HANNEMAN e RIDDLE, 2005).

Já a centralidade de intermediação mensura a capacidade de um indivíduo interligar outros dois atores não adjacentes. Dessa forma, estes últimos dependem do primeiro elemento (FREEMAN, 1979). Portanto, quanto maior o grau de centralidade, maior o controle potencial de um ator sobre os demais que dependem dele para interagir (ROSSONI e GUARIDO FILHO, 2007).

Diferentemente da centralidade, na qual o foco de análise reside nos atores participantes, nas medidas de coesão a atenção é voltada para as sub-redes formadas. Subgrupos coesos são aqueles que apresentam laços relativamente fortes, diretos e frequentes (WASSERMAN e FAUST, 1994). Scott (2000) argumenta que a forte coesão permite ao subgrupo possuir suas próprias normas, valores e orientações.

Duas são as métricas mais utilizadas para esta avaliação (WASSERMAN e FAUST, 1994): 1) mutualidade dos laços (clique); e, 2) proximidade e alcance entre os membros dos subgrupos (n-clique). A mutualidade identifica até que ponto as escolhas dos atores de um subgrupo são mútuas, em que $c l i-$ que representa uma sub-rede de três ou mais indivíduos totalmente conectados entre si (WASSERMAN e FAUST, 1994; SCOTT, 2000). Já o alcance avalia o número de intermediários existentes entre dois cliques distintos. Quanto menor o valor de $n$-cliques, mais rápido se torna o fluxo entre seus componentes.

Analisadas a centralidade e a coesão dos autores, foi investigada a existência de associação entre os indicadores de centralidade e a produção científica dos pesquisadores. Para essa análise, foi feito o uso da correlação $p$ de Spearman. Este teste não paramétrico foi usado porque os dados investigados não atendiam a todos os pressupostos para o emprego de análises paramétricas.

\section{ANÁLISE E DISCUSSÃO DOS RESULTADOS}

Nesta seção do trabalho, serão apresentados e discutidos os resultados encontrados. Primeiramente, avaliou-se a evolução dos artigos e as redes de co-autorias observadas no período em análise. Em seguida, os autores com produção científica na área de Pesquisa e Ensino em Contabilidade foram categorizados de acordo com o volume e a regularidade de sua publicação. Por fim, os indicadores de centralidade (degree, betweenness e closeness) são explorados, bem como se verifica a existência de associação entre esses indicadores e a produção científica dos autores e das redes de cooperação obtidas.

\subsection{A Evolução da árrea de Ensino e Pesquisa em Contabilidade}

O campo de estudo em Ensino e Pesquisa em Contabilidade mostrou sinal de avanço no período investigado. Com base nos 215 artigos selecionados, a comunidade acadêmica nessa área englobou 357 autores. No primeiro ano em análise, apenas três autores foram responsáveis pela publicação de dois artigos. Esse número contrasta com o último período analisado, no qual 45 foram os artigos produzidos por 100 autores. A Tabela 1 demonstra a evolução observada no período de análise, sendo complementada pela Figura 1. 
Tabela 1: Produção acadêmica acerca de Ensino e Pesquisa em Contabilidade no período analisado

\begin{tabular}{|c|c|c|c|c|c|c|}
\hline Ano & N. ${ }^{\circ}$ Artigos & N. ${ }^{\circ}$ Autores & N. ${ }^{\circ}$ Autorias & $\begin{array}{l}\text { N. }{ }^{\circ} \text { Artigos } \\
\text { Acumulados }\end{array}$ & $\begin{array}{l}\text { N. }{ }^{\circ} \text { Autores } \\
\text { Acumulados }\end{array}$ & $\begin{array}{l}\text { N. }{ }^{\circ} \text { Autorias } \\
\text { Acumuladas }\end{array}$ \\
\hline 1999 & 2 & 3 & 3 & 2 & 3 & 3 \\
\hline 2000 & 1 & 2 & 2 & 3 & 5 & 5 \\
\hline 2001 & 7 & 7 & 7 & 10 & 12 & 12 \\
\hline 2002 & 7 & 17 & 17 & 17 & 29 & 29 \\
\hline 2003 & 14 & 27 & 32 & 31 & 56 & 61 \\
\hline 2004 & 13 & 26 & 29 & 44 & 82 & 90 \\
\hline 2005 & 13 & 22 & 27 & 57 & 104 & 117 \\
\hline 2006 & 31 & 68 & 78 & 88 & 172 & 195 \\
\hline 2007 & 36 & 91 & 110 & 124 & 263 & 305 \\
\hline 2008 & 46 & 117 & 141 & 170 & 380 & 446 \\
\hline 2009 & 45 & 100 & 125 & 215 & 480 & 571 \\
\hline
\end{tabular}

Obs.: No número de autores evidenciados aqui não são excluídos aqueles que tiveram publicações nos anos anteriores. Dessa forma, o número final de autores acumulados superou o de 357 autores diferentes observados no presente estudo. Optou-se pela manutenção dos pesquisadores em anos posteriores à primeira publicação para totalizar todos os que publicaram artigos no respectivo ano e não somente os novos ingressantes no campo de pesquisa investigado. Já o número de autorias representa a soma do número de autores constantes em cada artigo, independente de um mesmo autor ter dois ou mais artigos no mesmo ano.

Fonte: Dados da Pesquisa

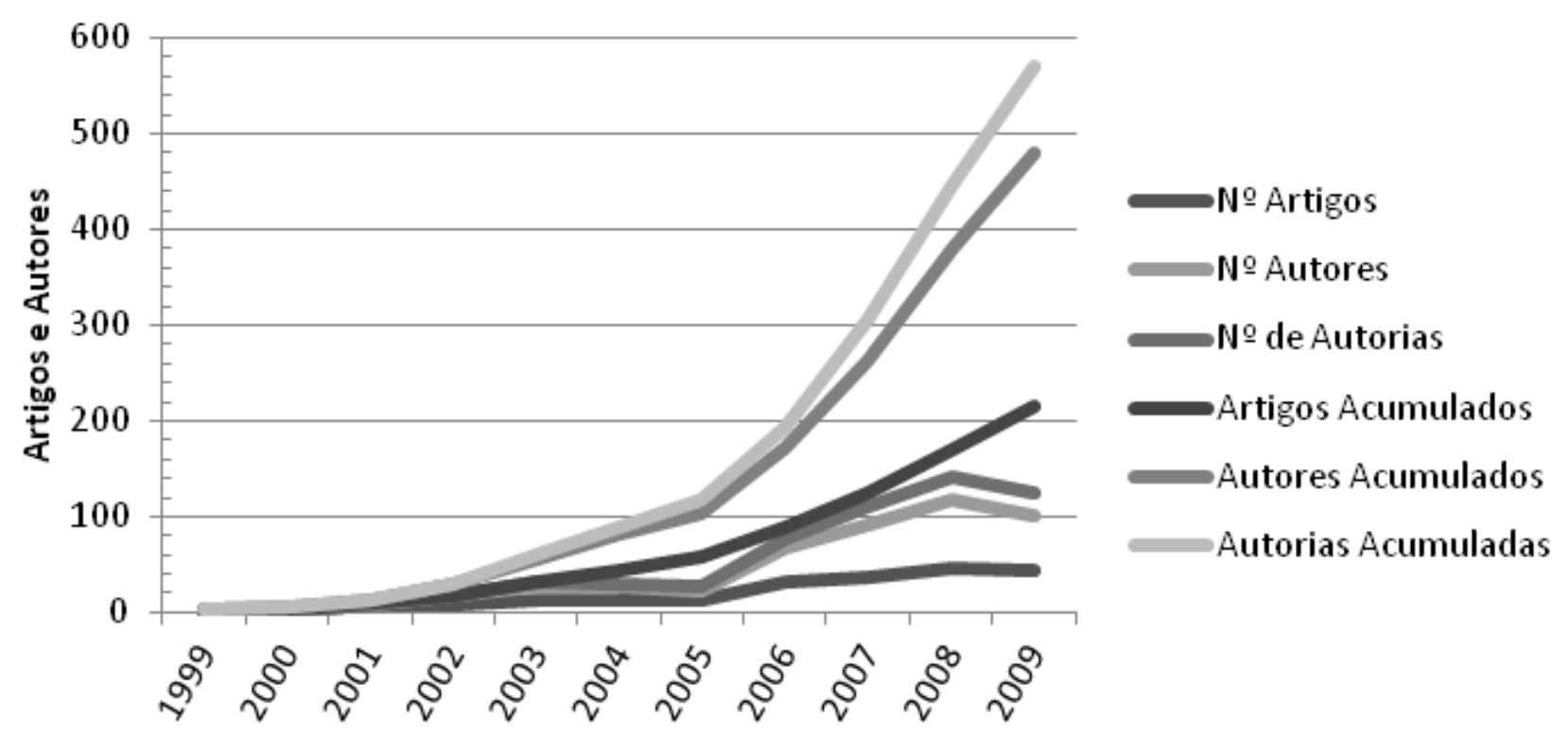

Figura 1: Evolução da Produção Acadêmica acerca do tema Ensino e Pesquisa em Contabilidade no Período Analisado

Fonte: Dados da Pesquisa

O número de artigos, apesar de manter-se praticamente constante nos dois últimos anos, apresentou crescimento nos períodos anteriores. Entretanto, o número de autores diminuiu de 2008 para 2009. Portanto, uma quantidade menor de pesquisadores foi responsável por manter constante a produção científica na área de Ensino e Pesquisa em Contabilidade. Na Tabela 2, estão ranqueados os autores que mais contribuíram para o campo temático pesquisado. 
Tabela 2: Autores com maior número de artigos publicados

\begin{tabular}{c|l|l|c}
\hline Ordem & \multicolumn{1}{|c|}{ Autor } & \multicolumn{1}{c|}{ IES } & $\mathbf{N}^{\mathbf{0}}$ Autorias \\
\hline $1^{\circ}$ & MARTINS, G. A. & FEA/USP & 13 \\
\hline $2^{\circ}$ & CORNACHIONE Jr., E. B. & FEA/USP & 11 \\
\hline \multirow{5}{*}{$3^{\circ}$} & CARDOSO, R. L. & Mackenzie & 7 \\
\cline { 2 - 4 } & LEITE FILHO, G. A. & UNIMONTES & 7 \\
\cline { 2 - 4 } & MURCIA, F. D. & UFSC & 7 \\
\cline { 2 - 4 } & PELEIAS, I. R. & FECAP & 7 \\
\hline \multirow{5}{*}{$7^{\circ}$} & CUNHA, J. V. A. & UFMG & 6 \\
\cline { 2 - 4 } & DOMINGUES, M. J. C. S. & FURB & 6 \\
\cline { 2 - 4 } & MENDONÇA NETO, O. R. & FEA/USP & 6 \\
\hline \multirow{5}{*}{$10^{\circ}$} & ANDRADE, J. X. & FEA/USP & 5 \\
\cline { 2 - 4 } & ARAUJO, A. M. P. & FEARP/USP & 5 \\
\cline { 2 - 4 } & BORBA, J. A. & UFSC & 5 \\
\cline { 2 - 4 } & NASCIMENTO, A. R. & FEA/USP & 5 \\
\cline { 2 - 4 } & NOVA, S. P. C. C. & FGV-SP & 5 \\
\cline { 2 - 4 } & OTT, E. & UNISINOS & 5 \\
\cline { 2 - 4 } & RICCIO, E. L. & FEA/USP & 5 \\
\cline { 2 - 4 } & SOUZA, M. A. & UNISINOS & \multicolumn{2}{|c|}{. } & 5 \\
\hline
\end{tabular}

Fonte: Dados da Pesquisa

Dentre os pesquisadores com maior número de artigos, dois se destacam dos demais: Gilberto de Andrade Martins, com 13 publicações, e Edgard Bruno Cornachione Jr., com 11. Estes autores foram os que mais contribuíram para a área de Ensino e Pesquisa em Contabilidade, em que 11,16\% dos trabalhos publicados tiveram a participação de um dos dois pesquisadores. Destaca-se que esses autores atuam como docentes em programas de pós-graduação.

Observa-se na Tabela 2, adicionalmente, que três grandes grupos foram formados, com 7, 6 e 5 artigos publicados. Tais grupos são integrados por 4, 3 e 8 pesquisadores, respectivamente. Considerando esses autores e os dois primeiros listados acima, mais da metade $(51,16 \%)$ dos estudos publicados nos Congressos investigados, versando sobre a área temática em questão, tiveram a participação desses autores.

A Faculdade de Economia e Administração da Universidade de São Paulo (FEA/USP) concentra a maior parte dos autores mais prolíficos -6 no total. Em seguida, aparecem a Universidade Regional de Blumenau (Furb), a Universidade Federal de Santa Catarina (UFSC) e a Universidade do Vale do Rio dos Sinos (Unisinos), com dois autores cada. Fato comum observado nessas IES é a existência de programas de pós-graduação na modalidade stricto sensu em Contabilidade, o que pode explicar a importância dessas instituições para o desenvolvimento do conhecimento científico na área investigada. A Tabela 3 apresenta o ranqueamento das IES por número de autorias. 
Tabela 3: Ranking de Instituições de Ensino Superior pelo Número de Autorias

\begin{tabular}{c|c|c|c|c|c|c|c|c|c|c|c|c}
\hline IES & $\mathbf{1 9 9 9}$ & $\mathbf{2 0 0 0}$ & $\mathbf{2 0 0 1}$ & $\mathbf{2 0 0 2}$ & $\mathbf{2 0 0 3}$ & $\mathbf{2 0 0 4}$ & $\mathbf{2 0 0 5}$ & $\mathbf{2 0 0 6}$ & $\mathbf{2 0 0 7}$ & $\mathbf{2 0 0 8}$ & $\mathbf{2 0 0 9}$ & Total \\
\hline FEA/USP & - & - & 4 & 1 & 9 & 17 & 8 & 14 & 15 & 30 & 13 & 111 \\
\hline UFSC & - & - & - & - & - & - & - & 10 & 15 & 13 & 1 & 39 \\
\hline Furb & - & - & - & - & 3 & - & 2 & 6 & 7 & 10 & 7 & 35 \\
\hline UFPE & - & - & - & 5 & 2 & - & - & 2 & 9 & 3 & 5 & 26 \\
\hline Unisinos & - & - & - & - & - & - & 2 & - & 5 & 7 & 8 & 22 \\
\hline UnB & - & - & - & - & - & - & - & 5 & 11 & 4 & 1 & 21 \\
\hline UFMG & - & - & - & - & 8 & - & - & 1 & 1 & 3 & 7 & 20 \\
\hline Fecap & - & - & - & - & 1 & - & 3 & 3 & 1 & 4 & 6 & 18 \\
\hline UFPR & - & - & - & - & - & 1 & - & 2 & - & 4 & 10 & 17 \\
\hline Fucape & - & - & 1 & - & 1 & 1 & - & 12 & - & - & - & 15 \\
\hline Mackenzie & - & - & - & - & 1 & 2 & - & - & 2 & 7 & 3 & 15 \\
\hline UFRJ & - & - & - & - & - & - & - & - & 5 & - & 10 & 15 \\
\hline UFRN & 1 & - & - & - & 3 & 1 & 2 & 1 & 3 & - & 2 & 13 \\
\hline UFC & 1 & - & 1 & - & - & - & - & - & 1 & 1 & 8 & 12 \\
\hline Fearp/USP & - & - & - & - & - & - & - & 1 & - & 4 & 5 & 10 \\
\hline UFBA & - & - & - & - & 2 & - & 2 & - & - & 4 & 2 & 10 \\
\hline UFPB & - & - & - & - & - & - & - & 2 & 2 & 1 & 5 & 10 \\
\hline Outras & 1 & 2 & 1 & 11 & 2 & 7 & 8 & 19 & 33 & 46 & 32 & 162 \\
\hline Total & 3 & 2 & 7 & 17 & 32 & 29 & 27 & 78 & 110 & 141 & 125 & 571 \\
\hline Das & & & & & & & & & \\
\hline
\end{tabular}

Fonte: Dados da Pesquisa

A IES que apresentou o maior número de autorias foi a FEA/USP, totalizando 111. Isso representa 19,44\% das autorias. Em seguida, observa-se a UFSC e a Furb, com 39 e 35 autorias, respectivamente. Todas as IES que obtiveram menos de 10 publicações foram agrupadas na categoria "Outras", totalizando 162 autorias. Esse número representa $28,37 \%$ do número de autorias. Isso demonstra que a área de Ensino e Pesquisa em Contabilidade recebe importante contribuição de diferentes instituições e não se encontra restrita a um pequeno número de universidades.

Destaca-se que, entre as IES mais prolíficas, nenhuma delas apresentou ao menos um artigo em todos os anos pesquisados. A FEA/USP também foi aquela que publicou um em maior número de anos 9 no total. Na sequência, a Universidade Federal do Rio Grande do Norte (UFRN) teve publicação em 7 anos diferentes. A IES que concentrou em um período menor as suas autorias foi a Universidade Federal do Rio de Janeiro (UFRJ), sendo 5 em 2007 e 10 em 2009.

\subsection{Categorização dos autores}

A categorização dos autores foi realizada com base em toda a sua atividade, nos congressos investigados, considerando o volume e regularidade de sua produção científica. Essa metodologia de classificação foi desenvolvida por Guarido Filho, Machado-da-Silva e Gonçalves (2009), adaptando as abordagens de Braun, Glanzel e Schubert (2001) e Gordon (2007). A Tabela 4 apresenta os critérios de classificação, bem como a quantidade de autores por categoria. 
Tabela 4: Distribuição de pesquisadores em categorias de Produção e Continuidade

\begin{tabular}{l|l|c|c|c}
\hline \multicolumn{1}{c|}{ Categoria } & \multicolumn{1}{|c|}{ Descrição } & Autores & AA & AA/Autores \\
\hline Continuantes & $\begin{array}{l}\text { Mais de uma publicação distribuída em cinco ou mais anos diferentes, } \\
\text { sendo ao menos uma nos últimos três anos. }\end{array}$ & $\begin{array}{c}5 \\
(1,40 \%)\end{array}$ & 42 & 8,4 \\
\hline Transientes & $\begin{array}{l}\text { Mais de uma publicação distribuída em não mais que quatro anos diferentes, } \\
\text { sendo ao menos uma nos últimos três anos e ao menos uma em anos anteriores. }\end{array}$ & $\begin{array}{c}35 \\
(9,80 \%)\end{array}$ & 122 & 3,49 \\
\hline One-timers & Apenas uma publicação em todo o período analisado. & $\begin{array}{c}260 \\
(72,83 \%)\end{array}$ & 260 & 1 \\
\hline Entrantes & $\begin{array}{l}\text { Mais de uma publicação em um ou mais anos diferentes, nos últimos três } \\
\text { anos (exclusivamente). }\end{array}$ & $\begin{array}{c}41 \\
(11,48 \%)\end{array}$ & 108 & 2,63 \\
\hline Retirantes & $\begin{array}{l}\text { Mais de uma publicação em um ou mais anos diferentes, mas sem } \\
\text { publicações nos últimos três anos. }\end{array}$ & $\begin{array}{c}16 \\
(4,49 \%)\end{array}$ & 39 & 2,4375 \\
\hline Total & & 357 & 571 & \\
\hline
\end{tabular}

Obs.: AA = Autorias em Artigos totaliza a presença dos autores nos trabalhos e, por este motivo, o seu valor total supere o número de artigos investigados; AA/Autores = apresenta o número de autorias em artigos dividido pelo número de autores de determinada categoria, refletindo assim a média de autorias em artigos por autor.

Fonte: adaptada de Guarido Filho, Machado-da-Silva e Gonçalves (2009) e dados da pesquisa.

Com relação ao alto volume de one-timer, destaca-se que eles poderão retornar ao campo de pesquisa investigado no futuro, como entrantes ou transientes (GUARIDO FILHO, MACHADO-DA-SILVA e GONÇALVES, 2009). Portanto, não se deve pensar, tão somente, que este número constitui pesquisadores que perderam o interesse na área após efetuarem uma publicação. Esta categoria de pesquisadores se destaca no universo dos artigos analisados, representando que, a cada 10 pesquisadores com publicações abordando assuntos com o tema Ensino e Pesquisa em Contabilidade - 7 são one-timers. Isso corrobora a grande dispersão dos atores que contribuem para a área ora estudada, aliado à premissa que norteia a Lei de Latko, de que alguns autores são responsáveis por muitos estudos, enquanto muitos pesquisadores publicam pouco.

Destaca-se ainda a participação de pesquisadores entrantes no conjunto de publicações investigadas. Dos 357 autores, 11,48\% estão enquadrados nesta categoria, sendo a segunda maior, em número de elementos. Isso leva a acreditar que existe um aumento do interesse dos estudiosos nessa área de pesquisa.

A importância da categoria dos pesquisadores continuantes pode ser observada, considerando a média de autorias por autor. O valor de 8,4 representa que, apesar do pequeno número de estudiosos enquadrados neste grupo, a sua produção científica é representativa. São autores que, por apresentarem publicações em um período longitudinal igual ou superior a cinco anos, podem demonstrar, em seus trabalhos, mudanças no campo de pesquisa em estudo.

\subsection{Redes de Co-autoria em Ensino e Pesquisa em Contabilidade}

A comunidade acadêmica responsável pelos 215 artigos investigados no presente estudo foi formada por 357 pesquisadores. Esses autores estão representados graficamente na Figura 3 pelos nós demonstrados nas redes. Os laços evidenciam o relacionamento existente entre os estudiosos.

Ao longo do período estudado, foi elaborada uma rede para cada ano, mantendo as relações observadas nos períodos anteriores. Esse procedimento auxilia na observação das alterações presenciadas na comunidade acadêmica. 

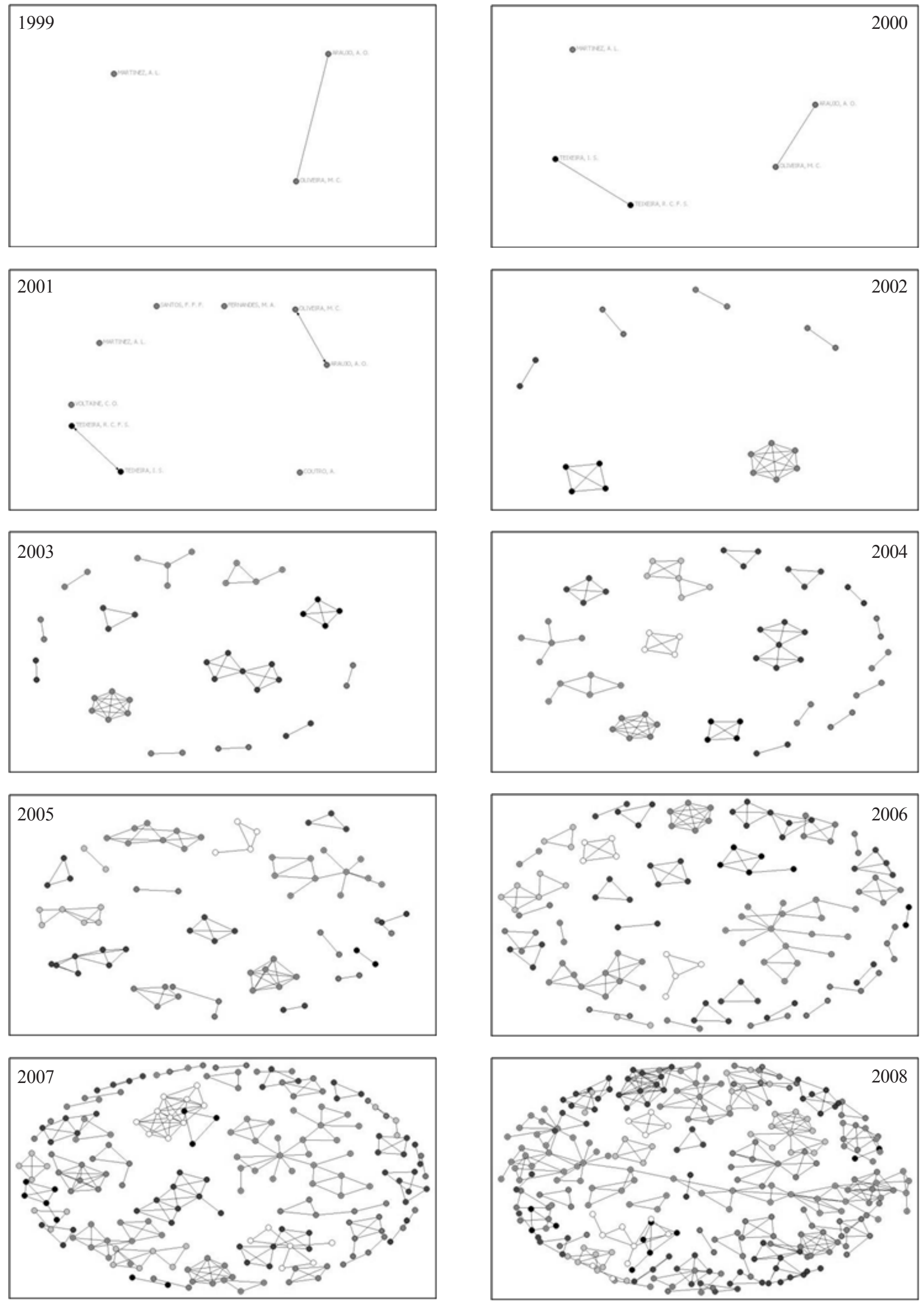


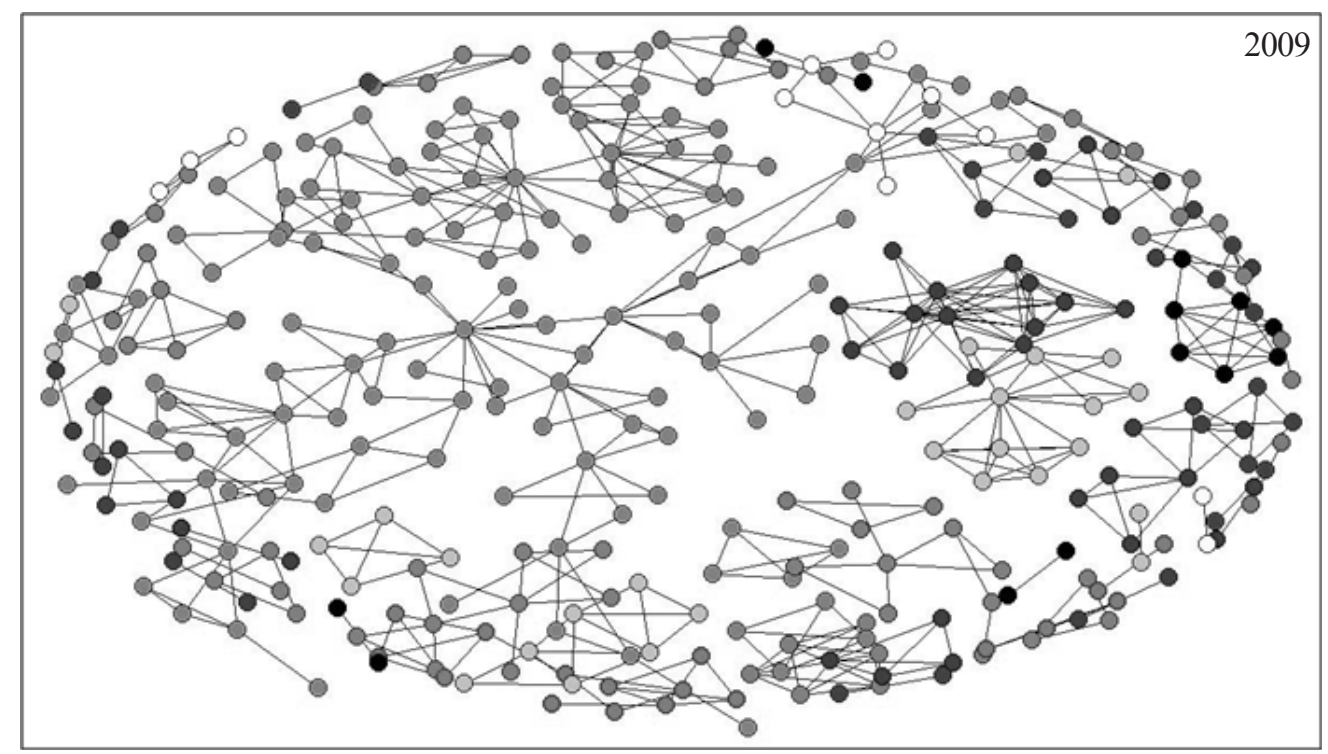

Figura 2: Evolução das Redes de Co-Autoria no Período Analisado

Fonte: Dados da Pesquisa

Nos três primeiros anos pesquisados, observa-se que as publicações eram desenvolvidas individualmente ou por dois autores em conjunto. A partir de 2002, pequenos grupos começam a se formar. Em 2003, o número de grupos aumenta e, nos anos subsequentes, verifica-se um aumento na quantidade de elementos em cada rede de co-autoria. Tal fato reitera as afirmações de outros autores sobre a ascensão das pesquisas em co-autoria (LABAND e TOLLISON, 2000; CRONIN, SHAW e LA BARRE, 2003; MOODY, 2004; ACEDO et al., 2006). Na Tabela 5, estão elencadas as características das redes de pesquisa formadas.

Tabela 5: Principais Características das Redes de Co-Autoria

\begin{tabular}{|c|c|c|c|c|c|c|}
\hline Ano & $\begin{array}{l}\text { Número de } \\
\text { Grupos }\end{array}$ & $\begin{array}{l}\text { Tamanho do } \\
\text { maior Grupo }\end{array}$ & $\begin{array}{c}\text { Número de } \\
\text { Autorias do } \\
\text { Maior Grupo }\end{array}$ & $\begin{array}{l}\text { Tamanho do } 2^{\circ} \\
\text { maior Grupo }\end{array}$ & $\begin{array}{c}\text { Número de } \\
\text { Autorias do } 2^{\circ} \\
\text { Maior Grupo }\end{array}$ & $\begin{array}{l}\text { Autores } \\
\text { Isolados }\end{array}$ \\
\hline 1999 & 1 & 2 & 2 & 0 & 0 & 1 \\
\hline 2000 & 2 & 2 & 2 & 2 & 2 & 1 \\
\hline 2001 & 2 & 2 & 3 & 2 & 2 & 8 \\
\hline 2002 & 6 & 6 & 6 & 4 & 4 & 11 \\
\hline 2003 & 13 & 7 & 8 & 6 & 6 & 14 \\
\hline 2004 & 17 & 7 & 8 & 6 & 7 & 21 \\
\hline 2005 & 19 & 11 & 24 & 8 & 10 & 29 \\
\hline 2006 & 35 & 17 & 43 & 10 & 14 & 42 \\
\hline 2007 & 46 & 26 & 60 & 10 & 16 & 68 \\
\hline 2008 & 54 & 49 & 113 & 13 & 18 & 107 \\
\hline 2009 & 60 & 70 & 161 & 44 & 76 & 142 \\
\hline
\end{tabular}

Fonte: Dados da Pesquisa

Na Tabela 5, pode-se observar a importância das redes de co-autoria para a área de Ensino e Pesquisa em Contabilidade. Em média, no período investigado, 26,4\% das autorias foram proporcionadas pelo maior grupo. Considerando os dois primeiros grupos, esta média sobe para $37,9 \%$. O maior grupo de 2009, com 161 autorias, foi responsável por 28,2\% das autorias acumuladas na amostra pesquisada. A Figura 3 e a Tabela 6 apresentam esta rede. 


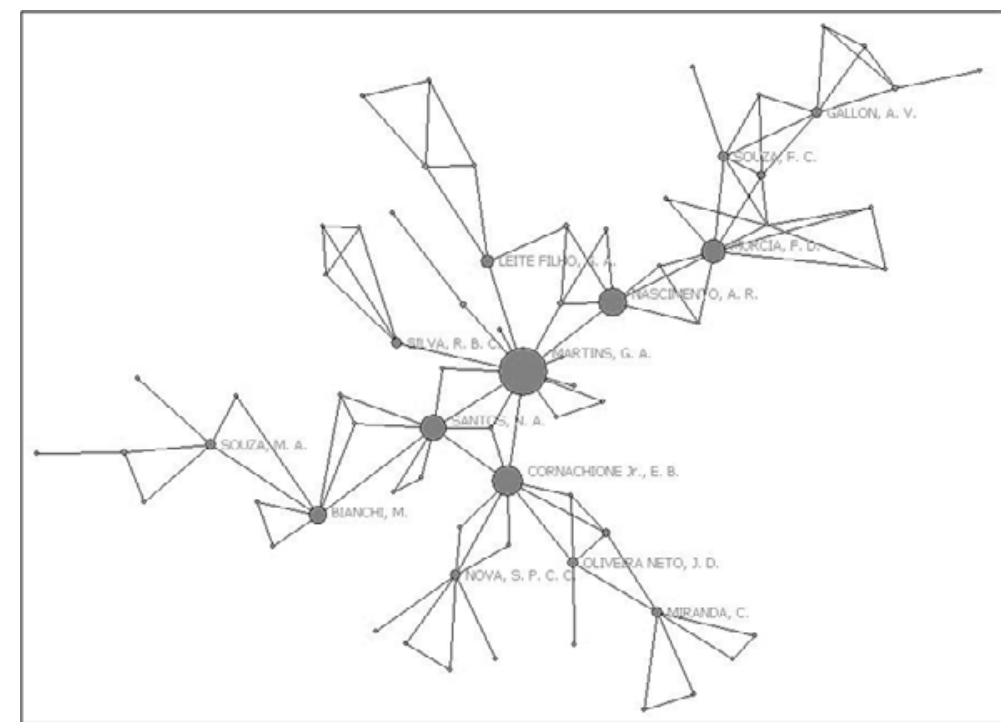

Figura 3: Principal Rede de Co-autoria

Fonte: Dados da Pesquisa

Na Figura 3, o tamanho de cada nó, que representa os autores que integram a rede de cooperação, foi definido pelo número de sua centralidade de intermediação (betweenness). Dessa forma, pode-se observar, graficamente, a importância de cada pesquisador no fluxo de informações existentes no grupo. Verifica-se, portanto, que o autor Martins apresenta a responsabilidade por um maior número de intermediações na principal rede de cooperação formada no período analisado. Outros autores, como Cornachione Jr, Santos, Nascimento e Murcia, realizam a intermediação entre estudiosos posicionados na região periférica da rede com o centro do grupo.

\section{Tabela 6: Distribuição de Autores da Principal Rede de Co-Autoria}

\begin{tabular}{|c|c|c|c|}
\hline Critério & Categoria & $\mathbf{N}^{0}$ de Autores & $\mathbf{N}^{0}$ de Autorias \\
\hline \multirow{5}{*}{$\begin{array}{l}\text { Número de Autores de Acordo } \\
\text { com a Categorização de Produção } \\
\text { e Continuidade }\end{array}$} & Continuantes & 2 & 24 \\
\hline & Transientes & 13 & 52 \\
\hline & One-Timers & 42 & 42 \\
\hline & Entrantes & 10 & 33 \\
\hline & Retirantes & 3 & 10 \\
\hline \multirow{9}{*}{$\begin{array}{l}\text { Número de Autores de Acordo } \\
\text { com a IES de vinculação }\end{array}$} & Fafibe & 2 & 3 \\
\hline & FEA/USP & 27 & 70 \\
\hline & Furb & 2 & 8 \\
\hline & UFRGS & 3 & 5 \\
\hline & UFRJ & 4 & 4 \\
\hline & UFSC & 11 & 28 \\
\hline & Unisinos & 5 & 12 \\
\hline & Univali & 2 & 2 \\
\hline & Outras & 14 & 29 \\
\hline
\end{tabular}

Obs.: As IES que apresentaram apenas um autor na rede de co-autoria foram concentradas na categoria "Outras", estando entre elas: Faculdade Machado de Assis; Fundação Getúlio Vargas (FGV-SP); Furg; Mackenzie; Universidade Estadual de Londrina (UEL); Universidade Federal de Minas Geris (UFMG); Universidade Federal de Pernambuco (UFPB); Universidade Federal do Piauí (UFPI); UFRN; Universidade Federal Rural do Rio de Janeiro (UFRRJ); Universidade Federal de Viçosa (UFV); Universidade de Montes Claros (Unimontes); e, Centro Universitário Unirg (Unirg).

Fonte: Dados da Pesquisa 
Em relação à categorização realizada na sessão anterior, considerando a Produção e a Continuidade dos autores, a principal rede de co-autoria na área de Ensino e Pesquisa em Contabilidade foi formada por pesquisadores classificados como one-timers. Contudo, destaca-se que, mesmo em maior número, esta categoria não obteve a maior quantidade de autorias. Os transientes, representados neste grupo por 13 autores, foram responsáveis $32,3 \%$ das autorias, com um total de 52 frente a 42 da primeira categoria. Finalmente, observa-se ainda que 11 dos autores mais prolíficos da área pertencem a esta rede de co-autoria.

Já em relação à IES de vinculação do estudioso, a FEA/USP foi a que apresentou um maior número de elementos. Essa instituição foi representada por 27 pesquisadores, os quais foram responsáveis por 70 autorias $(43,5 \%)$. A UFSC se destacou também, apresentando 11 autores neste grupo principal, os quais contribuíram com 28 autorias $(17,4 \%)$.

Para avaliar a contribuição das IES para a área temática de Ensino e Pesquisa em Contabilidade, foi desenvolvida a rede de co-autoria para o período estudado. Nesta nova rede, foi considerada apenas a IES de vinculação e não mais o nome do autor. A Figura 4 demonstra como as instituições se relacionam.

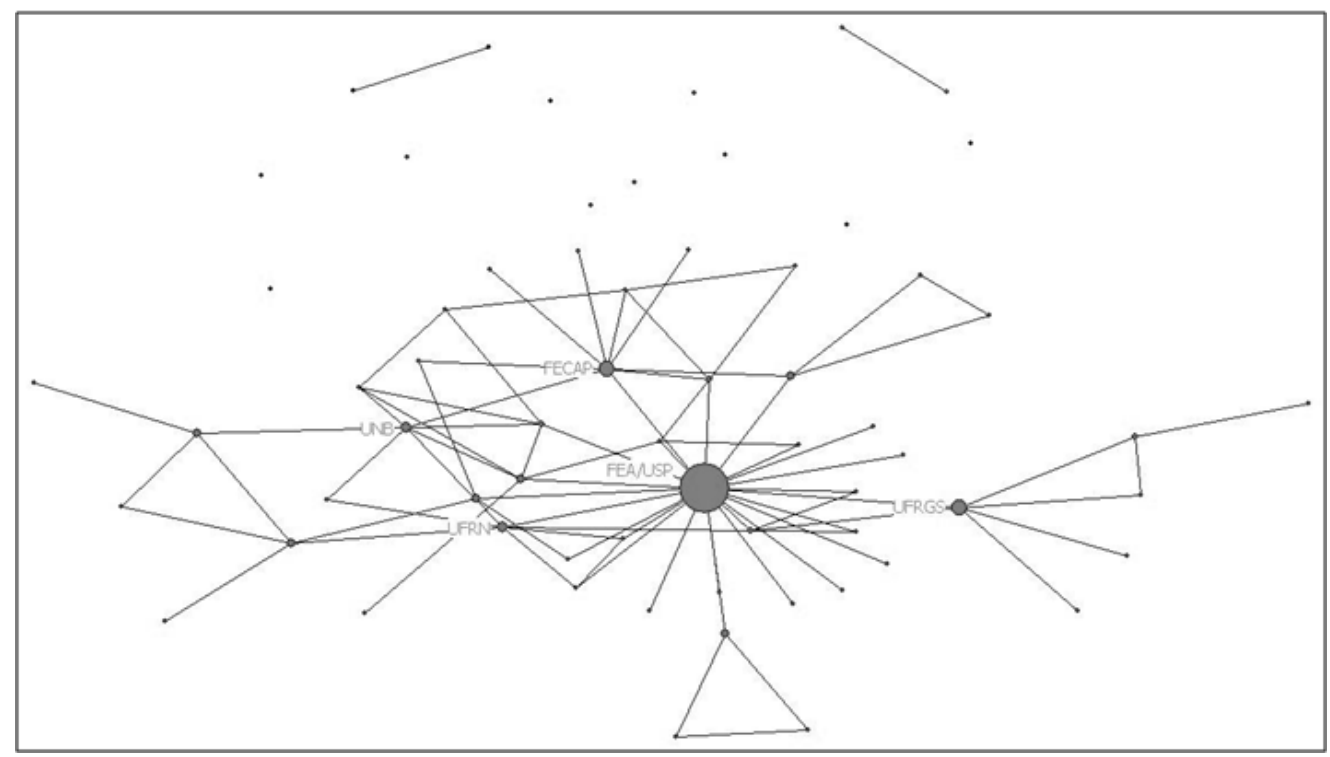

Figura 4: Rede de Co-autoria entre IES

Fonte: Dados da Pesquisa

Considerando a cooperação entre Instituições, foram formados 3 grupos de cooperação. Dois deles foram compostos por apenas duas IES, e o terceiro apresentou 50 elementos. Foi observada também a existência de instituições atuando de forma isolada, sem cooperar com outras. No total, 10 IES não tiveram autoria em conjunto com outros elementos. A existência de alta integração entre Instituições, no entendimento de Espartel, Basso e Rech (2008), proporciona maior contribuição para o campo de estudo, pois convergem diferentes visões dos problemas de pesquisa e de metodologias de trabalho.

Considerando a centralidade de intermediações (betweenness) realizadas pelas IES, verificou-se que a FEA/USP configurou entre a IES mais importante. Realizando a intermediação de instituições situadas perifericamente na rede de cooperação em Estudo e Pesquisa em Contabilidade, quatro outras IES se destacaram: Universidade de Brasília (UnB), Universidade Federal do Rio Grande do Sul (UFRGS), UFRN e Fundação Escola de Comércio Álvaro Penteado (Fecap). 


\subsection{Indicadores de Centralidade e Associação com a Produção Científica}

Nesta seção do trabalho, cada ator da rede foi avaliado pelos seus indicadores de centralidade e, posteriormente, investigou-se a existência de associação entre eles e a produção científica de cada elemento. Primeiramente, o enfoque foi nos pesquisadores e, posteriormente, nas instituições de vinculação.

A centralidade local (degree) avalia o número de relacionamentos diretos que cada autor possui. Isto é, mensura-se este indicador pelo número de laços locais que cada pesquisador possui. A Tabela 7 apresenta os 10 estudiosos que tiveram um maior degree.

Tabela 7: Os dez autores com maior centralidade local (degree)

\begin{tabular}{l|c}
\hline \multicolumn{1}{c|}{ Autor } & Degree \\
\hline CARDOSO, R. L. & 20 \\
\hline PELEIAS, I. R. & 19 \\
\hline MARTINS, G. A. & 19 \\
\hline LOPES, J. E. G. & 18 \\
\hline PEDENEIRAS, M. M. M. & 18 \\
\hline RIBEIRO FILHO, J. F. & 18 \\
\hline CORNACHIONE Jr., E. B. & 17 \\
\hline MURCIA, F. D. & 16 \\
\hline MENDONÇA NETO, O. R. & 15 \\
\hline DOMINGUES, M. J. C. S. & 15 \\
\hline
\end{tabular}

Fonte: Dados da Pesquisa

O estudioso que apresentou um maior número de relacionamentos diretos, ou seja, que obteve maior centralidade local foi Cardoso. Destaca-se que este autor figura, inclusive, entre os pesquisadores mais prolíficos da área. Peleias, e Martins, com um degree de 19 cada, figuraram em segundo lugar. Na sequência, em terceiro lugar, estão Lopes, Pederneiras, e Ribeiro Filho.

O segundo indicador pesquisado foi o que mede a centralidade de proximidade (closeness). Ele avalia a distância entre um ator e todos os demais elementos de uma mesma rede. Portanto, esse indicador verifica não só os relacionamentos diretos, mas também os indiretos. Os dez autores com maior centralidade de proximidade estão elencados na Tabela 8.

Tabela 8: Os dez autores com maior centralidade de proximidade (closeness)

\begin{tabular}{l|c}
\multicolumn{1}{c|}{ Autor } & Closeness \\
\hline MARTINS, G. A. & 34 \\
\hline CORNACHIONE Jr., E. B. & 31 \\
\hline SANTOS, N. A. & 30 \\
\hline PELEIAS, I. R. & 30 \\
\hline NASCIMENTO, A. R. & 28 \\
\hline CUNHA, J. V. A. & 26 \\
\hline MURCIA, F. D. & 26 \\
\hline DOMINGUES, M. J. C. S. & 26 \\
\hline JUNQUEIRA, E. R. & 25 \\
\hline BIANCHI, M. & 25 \\
\hline
\end{tabular}

Fonte: Dados da Pesquisa 
Na área de Ensino e Pesquisa em Contabilidade, Martins foi o que apresentou uma maior centralidade de proximidade. Na sequência, aparece Cornachione Jr. Nesse indicador, as duas primeiras posições foram preenchidas pelos autores mais prolíficos. Verifica-se ainda, que Cardoso, que apresentou maior centralidade local, não figura entre os dez pesquisadores com maior closeness.

Por fim, avaliou-se ainda o indicador de centralidade de intermediação (betweenness). A interação entre dois atores proporcionada por um terceiro elemento é objeto de análise deste indicador. A Tabela 9 elenca os pesquisadores que obtiveram um maior betweenness.

Tabela 9: Os dez autores com maior centralidade de intermediação (betweenness)

\begin{tabular}{l|c}
\multicolumn{1}{c|}{ Autor } & Betweenness \\
\hline MARTINS, G. A. & 1567 \\
\hline CORNACHIONE Jr., E. B. & 912 \\
\hline NASCIMENTO, A. R. & 889 \\
\hline SANTOS, N. A. & 759 \\
\hline MURCIA, F. D. & 743 \\
\hline PELEIAS, I. R. & 686 \\
\hline BIANCHI, M. & 500 \\
\hline DOMINGUES, M. J. C. S. & 296 \\
\hline LEITE FILHO, G. A. & 275 \\
\hline NOVA, S. P. C. C. & 266 \\
\hline
\end{tabular}

Fonte: Dados da Pesquisa

Assim como na centralidade de proximidade, no indicador que avalia a intermediação dos atores na rede os pesquisadores Martins e Cornachione Jr. ocuparam as primeiras posições. Os estudiosos listados na Tabela 9 representam aqueles que mais contribuem para o fluxo de conhecimento na área de Ensino e Pesquisa em Contabilidade.

A Tabela 10, abaixo, apresenta os mesmos indicadores de centralidade utilizados para avaliar os pesquisadores. Contudo, o foco desta vez concentra-se nas Instituições de vinculação dos autores.

Tabela 10: Indicadores de Centralidade das Instituições de Ensino Superior

\begin{tabular}{l|c|l|c|l|c}
\hline \multicolumn{2}{c|}{ Centralidade Local } & \multicolumn{2}{c|}{ Centralidade de Proximidade } & \multicolumn{2}{c}{ Centralidade de Intermediação } \\
\hline IES & Degree & IES & Closeness & IES & Betweenness \\
\hline FEA/USP & 50 & FEA/USP & 36 & FEA/USP & 846 \\
\hline UnB & 15 & Fecap & 27 & UFRGS & 227 \\
\hline UFPE & 11 & UFRN & 25 & Fecap & 227 \\
\hline Mackenzie & 10 & UFPB & 24 & UFRN & 125 \\
\hline UFRN & 10 & UFV & 24 & UnB & 122 \\
\hline UFCG & 10 & UFPE & 24 & UFC & 104 \\
\hline Fecap & 9 & Furb & 24 & FGV-SP & 94 \\
\hline Furb & 9 & UFRGS & 24 & Mackenzie & 94 \\
\hline UFMG & 8 & Mackenzie & 23 & UFPB & 79 \\
\hline UFV & 8 & UnB & 23 & Fearp/USP & 69 \\
\hline
\end{tabular}

Fonte: Dados da Pesquisa 
Nos três indicadores avaliados, a FEA/USP apresentou-se como a IES de maior centralidade. Salienta-se, ainda, que a diferença dos valores obtidos por esta instituição supera com folga os números apresentados pelos elementos que figuram em segundo lugar, principalmente na centralidade local e na de intermediação.

$\mathrm{Na}$ avaliação dos relacionamentos diretos, por meio do degree, a UnB foi aquela que se apresentou em segundo lugar, seguida pela UFPE. Na centralidade de proximidade, a Fecap e a UFRN completam, junto com a FEA/USP, as três primeiras posições. E, entre as IES que melhor contribuem para o fluxo de conhecimento, atuando como elementos importantes na intermediação entre as demais instituições, encontram-se a UFRGS e a Fecap, empatadas em segundo lugar, seguidas pela UFRN.

Para avaliar a existência de associação entre os indicadores de centralidade e a produção científica dos pesquisadores, foi utilizada a correlação $p$ de Spearman. Esse teste não paramétrico foi usado porque os dados investigados não atendiam a todos os pressupostos para o emprego de análises paramétricas. $\mathrm{O}$ resultado encontrado está sintetizado na Tabela 11.

\section{Tabela 11: Resultado da Correlação $p$ de Spearman}

\begin{tabular}{l|c|c|c}
\hline População Alvo & Variáveis & p de Spearman & .sig \\
\hline \multirow{3}{*}{ Pesquisadores } & Autorias x Degree & 0,618 & 0,000 \\
\cline { 2 - 4 } & Autorias x Closeness & 0,354 & 0,000 \\
\cline { 2 - 4 } & Autorias x Betweenness & 0,821 & 0,000 \\
\hline \multirow{2}{*}{$\begin{array}{l}\text { Instituições de } \\
\text { Ensino Superior }\end{array}$} & Autorias x Degree & 0,604 & 0,000 \\
\cline { 2 - 4 } & Autorias x Closeness & 0,492 & 0,000 \\
\cline { 2 - 4 } & Autorias x Betweenness & 0,678 & 0,000 \\
\hline
\end{tabular}

Fonte: Dados da Pesquisa

Considerando um coeficiente de significância de $5 \%$ (.sig $<0,05)$, o teste não paramétrico $p$ de Spearman demonstrou que existe associação entre os indicadores de centralidade e a produção científica dos elementos analisados, assim como observado em estudos anteriores (ROSSONI e GUARIDO FILHO, 2007; ROSSONI, HOCAYEN-DA-SILVA e FERREIRA Jr., 2008). Tal correlação foi encontrada tanto na investigação dos pesquisadores como das instituições a que eles são vinculados. Em todos os casos, o .sig foi menor que 0,001.

Para os pesquisadores, a associação entre autorias e centralidade local mostrou-se moderada, apresentando um coeficiente de correlação de 0,618. Diferentemente, a correlação existente entre produção científica e centralidade de proximidade foi fraca, cujo $p$ de Spearman foi de 0,354. O indicador de centralidade que apresentou uma associação mais forte foi o de intermediação. Seu coeficiente de correlação totalizou 0,821 . Portanto, de acordo com esta investigação, quanto mais o autor intermediar outros estudiosos, maior será a sua participação em trabalhos.

$\mathrm{Na}$ análise das Instituições de Ensino Superior, a associação entre o número de autorias e os indicadores de centralidade mostrou-se moderada. Esta classificação foi observada nas três métricas utilizadas. Todavia, assim como na avaliação de pesquisadores, a centralidade de intermediação foi a que apresentou um maior coeficiente de correlação $(0,678)$. Isso demonstra que, as IES que unem diferentes grupos, possibilitando assim a troca de conhecimentos, tende a ter uma quantidade maior de autorias.

\section{CONSIDERAÇÕES FINAIS}

O conhecimento científico é desenvolvido de forma social, por meio das relações existentes entre os atores que formam as redes entre as instituições de ensino superior (ROSSONI, HOCAYEN-DA-SILVA e FERREIRA Jr., 2008). Partindo desta premissa, o presente estudo objetiva mapear, por meio da análise de redes sociais, as interações colaborativas nos estudos desenvolvidos, versando sobre Ensino e Pesquisa em Contabilidade. Para isso, examinou-se um total de 215 de artigos coletados em congressos proeminentes para área contábil. 
A partir da análise dos dados, verificou-se um maior interesse dos pesquisadores pelo campo investigado, demonstrado pelo crescente número de artigos em cada ano que compôs a pesquisa empírica. Dentre os autores que mais se destacaram estão Gilberto de Andrade Martins e Edgard Bruno Cornachione Jr., os quais representam os estudiosos mais prolíficos. Ambos são vinculados à Universidade de São Paulo, Instituição de Ensino Superior responsável pelo maior número de autorias no período.

Realizando a categorização dos pesquisadores, de acordo com o seu volume e regularidade de publicações, verificou-se que a maior parte do número de autorias concentrou-se em autores que publicaram somente um artigo em todo o período analisado. Esses pesquisadores foram categorizados como one-timers. Isso demonstra a dispersão existente no campo de pesquisa, não estando concentrada, portanto, a produção científica em poucos autores. A categoria dos entrantes, formada por pesquisadores que contribuíram com mais de um trabalho exclusivamente nos últimos três anos investigados, foi a que obteve o segundo maior número de autorias. Este fato corrobora a ascensão do interesse pela área de Ensino e Pesquisa em Contabilidade.

Diferentes autores afirmam que o número de artigos feitos em parceria tem aumentado (LABAND e TOLLISON, 2000; CRONIN, SHAW e LA BARRE, 2003; MOODY, 2004; ACEDO et al., 2006). No estudo ora desenvolvido, foi verificado que este fenômeno ocorre também na área investigada. De acordo com o desenvolvimento das redes de colaboração, observou-se que, nos primeiros anos analisados, as pesquisas eram elaboradas por um ou, no máximo, dois autores em conjunto. Contudo, a partir do ano de 2002, grandes grupos de cooperação começaram a ser formados, a partir dos diversos estudos feitos em parceria.

Com base na análise realizada, verificou-se que as IES mais prolíficas na área temática pesquisada são aquelas que possuem programas de pós-graduação em Contabilidade. Além disso, os autores com maior número de artigos publicados e com maiores indicadores de centralidade são aqueles que figuram como docentes nesses programas de pós-graduação. Assim, é possível sugerir que o campo de pesquisa em Ensino e Pesquisa em Contabilidade tem como atores centrais professores de programas de pós-graduação na modalidade stricto sensu, que apresentam a área temática em questão a seus discentes, contribuindo para o significativo número de entrantes e o desenvolvimento verificado no campo de pesquisa investigado.

Por fim, investigou-se a existência de associação entre os indicadores de centralidade dos pesquisadores e das IES analisados com suas respectivas produções científicas. Para ambos os casos, foi observada correlação positivamente significativa. Contudo, com base na técnica de análise utilizada, não se pode afirmar que o aumento dos atributos de centralidade dos atores seja responsável direto pelo acréscimo no número de publicações do autor. Sugere-se, portanto, que exista uma dualidade no fenômeno investigado.

Adicionalmente, recomenda-se a ampliação do presente estudo, englobando também periódicos que não fizeram parte dessa análise preliminar. Dessa forma, poderia ser verificada a permanência das características aqui encontradas, utilizando-se uma amostra mais ampla de trabalhos. Propõe-se também uma comparação entre as redes colaborativas existentes na área de Ensino e Pesquisa em Contabilidade e de outros ramos do conhecimento contábil, a fim de descobrir a existência de padrões de pesquisa distintos.

\section{REFERENCIAS}

ACEDO, Francisco José; BARROSO, Carmen; ROCHA, Cristóbal Casanueva; GALÁN, José Luis. CoAuthorship in Management and Organizational Studies: An Empirical and Network Analysis. Journal of Management Studies, v. 43, n. 5, p.957-983, jul. 2006.

BARABASI, A. L.; JEONG, H.; NÉDA, Z.; RAVASZ, E; SCHUBERT, A.; VICSEK, T. Evolution of the social network of scientific collaborations. Physica A, v. 311, n. 3, p. 590-614, aug.2002.

BARNETT, Andy H.; AULT, Richard W.; KASERMAN, David L. The Rising Incidence of Co-authorship in Economics: Further Evidence. Review of Economics and Statistics, v. 70, n. 3, p. 539-543, aug. 1988. 
BATISTELLA, Flávio Donizete; BONACIM, Carlos Alberto Grespan; MARTINS, Gilberto de Andrade. Contrastando as Produções da Revista Contabilidade \& Finanças da (FEA-USP) e Revista Base (UNISINOS). Revista de Educação e Pesquisa em Contabilidade, v. 2, n. 3, p. 84-101, set./dez. 2008.

BORBA, José Alonso; MURCIA, Fernando Dal-Ri. Oportunidades para Pesquisa e Publicação em Contabilidade: Um Estudo Preliminar sobre as Revistas Acadêmicas de Língua Inglesa do Portal de Periódicos da CAPES. Brazilian Business Review, v. 3, n. 1, p. 88-103, jan./jun. 2006.

BRAUN, T., GLÄNZEL, W.; SCHUBERT, A. Publication and cooperation patterns of the authors of neuroscience journals. Scientometrics, v. 51, n. 3, p. 499-510, jul. 2001.

CRONIN, Blaise; SHAW, Debora; LA BARRE, Kathryn. Visible, Less Visible, and Invisible Work: Patterns of Collaboration in 20th Century Chemistry. Journal of the American Society for Information Science and Technology, v. 55, n. 2, p. 160-168, jan. 2003.

CRUZ, Ana Paula Capuano da; ESPEJO, Márcia Maria Bortolocci; GASSNER, Flávia Pozzera. Uma Análise da Evolução do Campo de Pesquisa em Contabilidade Gerencial sob a Perspectiva Colaborativa Mapeada em Redes Sociais. In: ENCONTRO DAANPAD, 33., 2009, São Paulo. Anais... São Paulo: ANPAD, 2009.

EMIRBAYER, Mustafa.; GOODWIN, Jeef. Network analysis, culture and the problem of agency. American Journal of Sociology, v. 99, n. 6, p. 1411-54, may 1994.

ESPARTEL, Lélis Balestrin; BASSO, Kenny; RECH, Eduardo. Co-autoria em Marketing no Brasil: Uma Análise dos Artigos Publicados no Enanpad e no EMA entre 1998 e 2007. In: ENCONTRO DAANPAD, 32., 2008, Rio de Janeiro. Anais... Rio de Janeiro: ANPAD, 2008.

ESPEJO, Márcia Maria dos Santos Bortolocci; CRUZ, Ana Paula Capuano da; WALTER, Silvana Anita; GASSNER, Flávia Pozzera. Campo de pesquisa em contabilidade: uma análise de redes sob a perspectiva institucional. Revista de Educação e Pesquisa em Contabilidade, v. 3, n. 2, p. 45-71, mai./ago. 2009.

FREEMAN, L. C. Centrality in social networks: Conceptual Clarification. Social Networks, v. 1, n. 3, p. 215-239, 1979.

GORDON, A. Transient and continuant authors in a research field: the case of terrorism. Scientometrics, v. 72, n. 2, p. 213-224, aug. 2007.

GRAEML, Alexandre Reis; MACADAR, Marie Anee; GUARIDO FILHO, Edson; ROSSONI, Luciano. Redes Sociais e Intelectuais em ADI: Uma Análise Cientométrica do Período 1997-2006. In: ENCONTRO DAANPAD, 32., 2008, Rio de Janeiro. Anais... Rio de Janeiro: ANPAD, 2008.

GUARIDO FILHO, Edson Ronaldo; MACHADO-DA-SILVA, Clóvis L.; GONÇALVES, Sandro Aparecido. Institucionalização da Teoria Institucional no Contexto dos Estudos Organizacionais no Brasil. In: ENCONTRO DA ANPAD, 33., 2009, São Paulo. Anais... São Paulo: ANPAD, 2009.

HANNEMAN, R. A.; RIDDLE, M. Introduction to Social Network Methods. Riverside: University of Califórnia, 2005. Disponível em: <http://faculty.ucr.edu/ hanneman/nettext/index.html> Acesso em: 10 maio 2010.

HUDSON, John. Trends in Multi-Authored Papers in Economics. The Journal of Economic Perspectives, v. 10, n. 3, 1996. 
KATZ, J. Sylvan.; MARTIN, Ben R. What is research collaboration? Research Policy. v.26, n. 1, p.1-18, mar. 1997.

LABAND, David N.; TOLLISON, Robert D. Intellectual Collaboration. The Journal of Political Economy, v. 108, n. 3, p. 632-662, jun. 2000.

LEITE FILHO, Geraldo Alemandro. Padrões de produtividade de autores em periódicos e congressos na área de contabilidade no Brasil: um estudo bibliométrico. In: Congresso USP de Controladoria e Contabilidade, 6., 2006, São Paulo. Anais ... São Paulo: FEA/USP, 2006. CD-ROM.

LIU, Xiaoming; BOLLEN, Johan; NELSON, Michael L.; VAN DE SOMPEL, Herbert. Co-authorship networks in the Digital Library Research Community. Information Processing \& Management, v. 41, p. 1462-1480, 2005.

LYRIO, Maurício Vasconcellos Leão; BORBA, José Alonso; COSTA, Jeane Maria da. Controle Gerencial: Delineamento do Perfil Metodológico de uma Amostragem de Publicações Acadêmicas nas Áreas de Administração e Contabilidade de 2000 a 2004. BASE - Revista de Administração e Contabilidade da Unisinos, v. 4, n. 2, 126-136, mai./ago.2007.

MACHADO, Márcia Reis; NASCIMENTO, Artur Roberto do; MURCIA, Fernando Dal-Ri. Análise Crítica - Epistemológica da Produção Científica em Contabilidade Social e Ambiental no Brasil. In: CONGRESSO USP DE CONTROLADORIA E CONTABILIDADE, 9., 2009, São Paulo. Anais... São Paulo: FEA/USP, 2009.

MARTELETO, Regina Maria. Análise de Redes Sociais: Aplicação nos Estudos de Transferência de Informações. Ci. Inf., v. 30, n. 1, p. 71-81, jan./abr. 2001.

MOODY, James. The Structure of a Social Science Collaboration Network: Disciplinary Cohesion from 1963 to 1999. American Sociological Review, v. 69, n. 2, p. 213-238, apr. 2004.

NASCIMENTO, Artur Roberto do; RIBEIRO, Daniel Cerqueira; JUNQUEIRA, Emanuel R.. Estado da Arte da Abordagem Comportamental da Contabilidade Gerencial: Análise das Pesquisas Internacionais. In: CONGRESSO USP DE CONTROLADORIA E CONTABILIDADE, 8., 2008, São Paulo. Anais... São Paulo FEA/USP, 2008.

NELSON, Reed. Uso da Análise de Redes Sociais no Estudo das Estruturas Organizacionais. Revista de Administração de Empresas, v. 24, n. 4, p. 150-157, out./dez. 1984.

NEWMAN, M. E. J. Scientific collaboration networks. I. Network construction and fundamental results. Physical Review E, v. 64, 16131, p. 1-8, 2001.

ROSSONI, Luciano; GUARIDO FILHO, Edson Ronaldo. Cooperação Interinstitucional no Campo de Pesquisa em Estratégia. Revista de Administração de Empresas, v. 47, n. 4, p. 74-88, out./dez. 2007.

ROSSONI, Luciano; MACHADO-DA-SILVA, Clóvis Luis. Coesão estrutural e construção do conhecimento científico no campo da Estratégia. In: ENCONTRO DE ESTUDOS EM ESTRATÉGIA, 3., 2007, São Paulo. Anais... Rio de Janeiro: ANPAD, 2007. 
ROSSONI, Luciano; HOCAYEN-DA-SILVA, Antônio João; FERREIRA Jr.; Israel. Aspectos Estruturais da Cooperação entre Pesquisadores no Campo da Administração Pública e Gestão Social: Análise das Redes entre Instituições no Brasil. Revista de Administração Pública, v. 42, n. 6, p. 10411067, nov./dez. 2008.

SCOTT, J. Social Network Analysis: A Handbook. 2. ed. London: Sage Publications, 2000.

SOUZA, Flávia Cruz de Souza; SULIANI, Rover; GALLON, Alessandra Vasconcelos; ENSSLIN, Sandra Rolim. Análise das IES da Área de Ciências Contábeis e de seus Pesquisadores por meio de sua produção científica. Revista Contabilidade Vista e Revista, v. 19, n. 3, p. 15-38, jul./set. 2008.

VOOS, H. Lotka and Information Science. Journal of the American Society of Information Science, New York, v. 25, p. 270-272, July/Aug. 1974.

WAKEFIELD, Robin. Networks of accounting research: A citation-based structural and network analysis. The British Accounting Review, v. 40, p. 228 - 244, 2008.

WALTER, Silvana Anita; SILVA, Eduardo Damião da. Visão Baseada em Recursos: um Estudo Bibliométrico e de Redes Sociais da Produção Científica da Área de Estratégia do EnANPAD 1997-2007. In: ENCONTRO DA ANPAD, 32., 2008, Rio de Janeiro. Anais... Rio de Janeiro: ANPAD, 2008.

WASSERMAN, S.; FAUST, K. Social Network Analysis: Methods and Applications. Cambridge: Cambridge University Press, 1994.

WELLMAN, Barry. Structural Analysis: From method and metaphor to theory and substance. In: WELLMAN, B.; BERKOWITZ, S. D. Social Structures: a network approach. Cambridge: Cambridge University Press, 1988. 